\title{
Alexa Rank Sebagai Alat Ukur Popularitas Website Crowdfunding
}

\author{
Untung Rahardja ${ }^{1}$ \\ Qurotul Aini ${ }^{2}$ \\ Yustin Novita Dewi ${ }^{3}$
}

\author{
Dosen STMIK Raharja ${ }^{1,2}$, Mahasiswa STMIK Raharja ${ }^{3}$ \\ E-mail: untung@ raharja.info ${ }^{1}$, aini@ raharja.info ${ }^{2}$, yustin@ raharja.info ${ }^{3}$
}

\begin{abstract}
ABSTRAK
Pengguna internet yang drastis di seluruh penjuru dunia saat ini membuat semua hal berubah sangat cepat. Dalam penggunaan internet yang berkembang saat ini salah satunya adalah website. Untuk menentukan nilai sebuah website dibutuhkan popularitas untuk menunjangnya. Dapat dilihat dari pemeringkatan web terutama pada website crowdfunding, website yang bergerak di bidang peng galangan dana yang menyajikan informasi dan interaksi didalamnya. Untuk dapat mengetahui peringkat dalam sebuah website, dapat menggunakan Alexa Rank sebagai alat ukur pemeringkatannya. Dalam penelitian ini menggunakan metode pengumpulan data dengan dilakukan 7 (tujuh) literature survey tentang pemeringkatan website diantaranya terkait dengan penggunaan Alexa Rank. Sebuah popularitas dapat di buktikan dengan menggunakan Alexa Rank melalui 3 (tiga) fasilitas Alexa Rank yang dapat digunakan dengan mudah. Hasil akhir penelitian ini dilakukan dengan penggunaan fasilitas yang di sediakan Alexa Rank untuk mengetahui, memantau maupun memonitoring popularitas website crowdfunding.
\end{abstract}

Kata kunci: Website, Website Crowdfunding, Alexa Rank

\begin{abstract}
Internet users who drastically throughout the world today makes all things change very quickly. In the growing use of the internet at this time one of them is the website. To determine the value of a website's popularity is required for menunjangnya. It can be seen from the web ratings mainly on the website of crowdfunding, website in the fundraising that present information and interactions within. To be able to know the ranking in a website, it can use the Alexa Rank as a measuring instrument pemeringkatannya. In this study using the method of data collection was done with 7 (seven) literature survey about the ranking of websites which were associated with the use of the Alexa Rank. A popularity can be proved by using the Alexa Rank through three (3) Alexa Rank facilities that can be used easily. The end result of this research was conducted with the use of facilities that provide Alexa Rank to discover, monitor or monitor crowdfunding website popularity.
\end{abstract}

Keywords: Website, Website Crowdfunding, Alexa Rank

29 | Untung, Qurotul, Yustin - Alexa Rank Sebagai Alat Ukur Popularitas... 


\section{PENDAHULUAN}

Pemanfaatan teknologi di berbagai sektor sudah dapat diterapkan dan yang saat ini sedang berkembang adalah teknologi website. Website atau situs merupakan media informasi berupa kumpulan halaman-halaman teks, gambar, suara, video, adapun semuanya yang tergabung dan terangkum dalam sebuah domain atau subdomain yang bertempatan di dalam internet. Sebuah situs dapat berperan menjadi sarana interaksi manusia ataupun perusahaan, baik dengan pihak luar maupun kalangan sendiri. Selain itu, situs juga dapat berfungsi untuk menggalang komunitas atau semacamnya. Karena itulah, seharusnya manusia dituntut selalu berpikir apa yang menjadi tujuan dasar dari dibangunnya sebuah situs. Jika situs tersebut memang ditujukan untuk kalangan umum yang tidak terbatas, suka atau tidak suka ada tuntutan untuk mempopulerkan situs tersebut.

Salah satu strategi yang dapat digunakan dalam peningkatan popularitas dalam web adalah memperkaya informasi pada website yang dimiliki. Dengan adanya informasi yang cukup banyak maka website tersebut mudah untuk di index oleh mesin pencari. Sebuah website mempunyai kinerja terhadap search engine. Semakin baik maka akan mempermudah website mendapat pengunjung. Namun demikian tidak hanya cukup memperkaya informasi pada website tersebut, pihak lembaga juga harus mengetahui strategi SEO (Search Enggine Optimization).

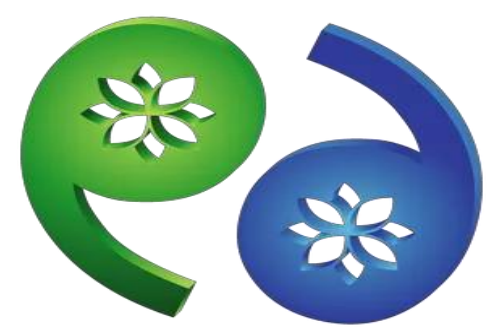

Gambar 1. Logo Pribadi Dermawan

Sumber : http://pribadidermawan.org/ [1]

Website crowdfunding tentunya memerlukan popularitas guna menambah kepercayaan terhadap kegiatan yang ada pada website. Dimana website crowdfunding merupakan website yang bergerak di bidang pendanaan sosial. Pada dasarnya website crowdfunding menjadikan media yang digunakan donatur untuk menyumbangkan dananya. Kepercayaan masyarakat sangat di perlukan dalam hal ini. Seperti pada website Pribadi Dermawan yaitu pribadidermawan.org yang merupakan website crowdfunding yang ingin menyebarkan cinta terhadap sesama tanpa pilih kasih. Oleh sebab itu, kepopuleran sebuah website sangat berhubungan dengan hal ini. Faktor pengguna internet yang ada di Indonesia juga berpengaruh terhadap tingkat popularitas sebuah website.

30 | Untung, Qurotul, Yustin - Alexa Rank Sebagai Alat Ukur Popularitas... 


\section{PERMASALAHAN}

Dikutip dari Wikipedia, Rank is the relative position, value, worth, complexity, power, importance, authority, level, etc. of a person or object with in a ranking [2]. Rank dalam sebuah website sangatlah berpengaruh dalam kelangsungan hidup website tersebut, karena semakin tinggi rank website tersebut maka hal tersebut akan meyakinkan para pengunjung lain untuk datang ke website tersebut. Untuk meningkatkan rank pada website di butuhkan strategi dalam pencapaian peningkatan rank yang di inginkan serta aktivitas di dalam website, aktivitas sering terjadi dengan pemanfaatan dari sebuah artikel yang menimbulkan diskusi seperti komentar artinya terdapat pengunjung yang datang ke website tersebut. Website crowdfunding Pribadi Dermawan masih merupakan website muda alias website baru, dimana website ini baru menginjak 4 (empat) bulan dari dibuatnya domain pribadidermawan.org dan belum ada aktivitas yang signifikan didalamnya.

Alat bantu pemeringkatan website Alexa Rank dapat berfungsi sebagai pengukur keberhasilan dan keefektifan dalam menyebarkan informasi serta layanan berdonasi pada website Pribadi Dermawan. Alexa rank merupakan indikator penting untuk membandingkan situs web dengan situs yang lain, alexa memungkinkan untuk membandingkan website hingga mendapatkan rincian perbandingan dalam grafik. Alexa rank dapat memberikan informasi mengenai traffic peringkat website, data trafik tersebut diambil melalui toolbar alexa pada browser pengunjung website atau blog tersebut. Setiap website atau blog memiliki jumah rank alexa yang berbeda-beda. Jika suatu website atau blog memiliki ranking website yang rendah maka semakin bagus ranknya namun jika alexa rank websitenya tinggi artinya trafik website tersebut rendah. Oleh karena itu Alexa Rank dapat diartikan sebagai sebuah alat bantu untuk melihat peringkat terhadap sebuah website atau blog berdasarkan trafik atau banyaknya pengunjung yang diberikan atau dibuat oleh alexa.com.

\section{METODE PENELITIAN}

Dalam proses penelitian ini, menggunakan metode pengumpulan data sebagai penerapan metode penelitian yang dilakukan untuk mengidentifikasikan kesenjangan, menghindari pembuatan ulang, mengidentifikasikan metode yang pernah dilakukan, serta mengetahui orang lain yang spesialisasi dan area penelitian yang sama di bidang ini.

\subsection{Metode Pengumpulan Data}

Metode pengumpulan data merupakan teknik yang dilakukan untuk mengumpulkan data. Proses penelitian yang dilakukan dengan metode pengumpulan data untuk mendapatkan informasi mengenai objek penelitian yang diteliti. Seperti yang telah diketahui, data merupakan fakta atau bagian dari fakta yang mengandung arti yang 
dihubungkan dengan kenyataan, simbol-simbol, gambar-gambar, kata-kata, angkaangka atau huruf-huruf yang menunjukkan suatu ide, obyek, kondisi atau situasi dan lain-lain. Data yang diperoleh dari proses pengumpulan data akan diolah menjadi sebuah informasi. Menurut Pernyataan yang dikemukakan oleh Gordon B. Davis (1974) dalam buku Yakub dan Vico Hisbanarto (2014:18) Informasi adalah hasil pengolahan dari data menjadi suatu bentuk yang dapat berguna bagi si penerima dan memiliki nilai nyata dan dapat dirasakan dalam keputusan yang akan datang. Metode pengumpulan data memiliki beberapa tahapan, diantaranya :

\subsubsection{Observasi (Pengamatan)}

Salah satu metode yang dapat diterapkan guna proses untuk mengumpulkan data adalah melalui metode observasi atau pengamatan. Metode observasi adalah metode yang dilakukan dengan cara melakukan pengamatan secara langsung kepada proses berjalannya sistem.

\subsubsection{Studi Pustaka}

1. Penelitian yang dilakukan oleh Rahayu Widayanti, Dwi Safiroh Utsalina pada tahun 2015 yang berjudul "Analisis Situs Web Perusahaan Jasa Pengiriman Barang Menggunakan Perangkat Pemeringkatan Alexa". Penelitian ini memiliki tujuan yaitu untuk menganalisis situs web perusahaan jasa pengiriman barang menggunakan perangkat pemeringkatan Alexa. Hasil penelitian menunjukkan bahwa dari 3 situs web yang dianalisis disisi popularitas www.jne.co.id berada pada peringkat yang lebih baik dibandingkan dengan www.posindonesia.com, dan www.tiki-online.com. [3]

2. Penelitian yang dilakukan oleh Untung Rahardja, Qurotul Aini, Rista Meytasari pada tahun 2017 yang berjudul "Pemanfaatan Fungsi Etalase Artikel Untuk Meningkatkan Traffic Rank Website ZPreneur". Dalam penelitian ini, penulis mendapatkan 3 (tiga) masalah yang dihadapi perihal meningkatkan traffic rank website ZPreneur. Dalam tahap meningkatkan kualitas maka dimanfaatkan fungsi etalase artikel di ZPreneur. Untuk meningkatkan traffic rank ZPreneur serta menunjang perkembangan ZPreneur maka Tahap implementasi yang dilakukan adalah dengan mengelola etalase artikel yang telah dibuat oleh para anggota (ZP'er). Sehingga menghasilkan kegiatan pemantauan guna meningkatkan rank website ZPreneur dengan menggunakan Alexa Rank. [4]

3. Penelitian yang dilakukan oleh Andri Prasetyo, Linda Suvi Rahmawati, pada tahun 2015 yang berjudul "Analisis Website Toko Online". Hasil analisis perhitungan menggunakan tools Page Rank berdasarkan jumlah pengunjung yang mengunjungi www.belbuk.com mempunyai nilai 3 dari 10 dan Alexa Rank mempunyai nilai 193, 245 dan di Indonesia mempunyai nilai 2,005 maka bisa disimpulkan bahwa website www.belbuk.com masih mempunyai Jurnal 
Teknologi Informasi Vol. 6 No. 122 pengunjung yang sedikit. Website belum terkenal dan perlu dikaji lagi untuk pengembangannya. [5]

4. Penelitian yang dilakukan oleh Dien Novita, pada tahun 2016 yang berjudul "Analisis Popularitas Website Pemerintah Daerah Di Sumatera Selatan". Tujuan dari penelitian ini adalah untuk menilai peringkat popularitas dari web pemerintah daerah di Sumatera Selatan dengan menggunakan perangkat Alexa untuk 3 parameter, yaitu Global Rank, Bounce Rate, dan Total Link. Hasil penelitian menunjukkan tingkat popularitas tertinggi yaitu website Pemerintah Kabupaten Banyuasin untuk parameter Bounce Rate dan Total Link. Sedangkan website Pemerintah Kota Palembang, tingkat popularitas tertinggi untuk parameter Global Rank. Hasil penilaian ini diharapkan menjadi tolok ukur untuk meningkatkan kualitas layanan pemerintah terhadap masyarakat. [6]

5. Penelitian yang dilakukan oleh Untung Rahardja, Qurotul Aini, Lily Ratna Sulastrini, pada tahun 2017 dengan judul "Penerapan Inbound Official Site Sistem Informasi Untuk Meningkatkan Rank Webometrics". Dalam penelitian ini permasalahan yang dihadapi adalah perihal inbound untuk website Sistem Informasi, karena dengan adanya banyak inbound tentunya akan membuat official site Sistem Informasi lebih dikenal lagi khususnya bagi para Pribadi Raharja jurusan Sistem Informasi sebagai wadah untuk mendapatkan informasi yang akurat. Hasil akhir penelitian ini dilakukan dengan cara menggunakan webometrics untuk memantau rank pada website raharja.ac.id. [7]

6. Penelitian yang dilakukan oleh Untung Rahardja, Endah Nirmala Dewi, Ninda Lutfiani pada tahun 2017 yang berjudul "Peningkatan Rank Webometrics Menggunakan Metode Inbound Dan Outbound Pada Perguruan Tinggi”. Webometrics memberikan informasi mengenai kualitas suatu web universitas yang didukung dengan adanya subdomain dari domain utama yang dimiliki setiap universitas yang sudah mendaftarkan untuk bisa masuk dalam ranking webometrics ini. Semakin kecil rank yang di dapat maka semakin besar peluang untuk menduduki peringkat atas. Adapun kriteria atau level yang dibuat menggunakan metode pendekatan obyek 10 level inbound, hal ini untuk memudahkan penyebaran link agar sesuai dengan target yang diharapkan dan lebih meluas sehingga mencapai hasil yang maksimal untuk mencapai predikat perguruan tinggi yang masuk dalam World Class University (WCU). [8]

7. Penelitian yang dilakukan oleh Arjun Thakur, A. L. Sangal, Harminder Bindra pada tahun 2011 yang berjudul "Quantitative Measurement and Comparison of Effects of Various Search Engine Optimization Parameters on Alexa Traffic Rank". Penelitian ini membahas tentang pertimbangkan untuk menggunakan SEO (Search Engine Optimization) untuk meningkatkan lalu lintas situs Web. dimaksudkan untuk membantu webmaster dan pemasaran suatu perusahaan 
dalam meningkatkan ATR dari website perusahaan. Peningkatan ATR akan menyebabkan lebih banyak keuntungan di secara online. [9]

8. Penelitian yang dilakukan oleh Achmad Solihin (2011). Penelitian ini mengenai "Strategi Peningkatan Peringkat Perguruan Tinggi di Webometric: Studi kasus Universitas Budi Luhur" penelitian ini menggunakan metode strategi langkahlangkah (action) pencapaian, yaitu yang berkaitan dengan teknis, kebijakan, content atau isi serta pendukung. Dari penjelasan diatas dapat disimpulkan strategi yang digunakan untuk meningkatkan peringkat webometric terdapat 4 kategori yakni yang berkaitan dengan kebijakan, content, teknis serta langkah pendukung. [10]

9. Penelitian yang dilakukan oleh Yuhefizar, Mochamad Hariadi, Yoyon K Suprapto pada tahun 2011 yang berjudul "Peringkat Website Perguruan Tinggi Berbasis Analisa Hyperlink Menggunakan Factor Analysis". Penelitian ini menggunakan 25 website perguruan tinggi di Indonesia yang menduduki posisi teratas dalam peringkat webometrics edisi Januari 2011 sebagai obyek penelitian. Data hyperlink diperoleh dengan memanfaatkan dua mesin pencari, google.com dan yahoo.com, kemudian data hyperlink ini di analisa menggunakan metode Factor Analysis. Dari hasil analisa diperoleh bahwa peran dari faktor total hyperlink $(0,254)$ dan faktor eksternal hyperlink $(0,253)$ sangat mempengaruhi kualitas sebuah website ditinjau dari segi hyperlink dengan analisa faktor. [11]

10. Penelitian yang dilakukan oleh Sindy Nova, pada tahun 2014 dengan judul "Analisis Tingkat Kepopuleran Website Dalam Penyebaran Informasi Dan Layanan Publik Pada PT. Lion Air, PT. Garuda Indonesia dan PT. Sriwijaya”. Tujuan penelitian ini adalah mendapatkan gambaran mengenai subdomain dan fitur yang paling banyak dikunjungi dan digunakan oleh masyarakat dari tiga website maskapai penerbangan di Indonesia yaitu PT Lion Air, PT Garuda Indonesia dan PT Sriwijaya Air, dilihat dari respon pengguna. Langkah yang dilakukan yaitu dengan melakukan Kajian Pustaka, Penentuan objek penelitian, Eksplorasi dari objek penelitian, Analisis web menggunakan alat bantu pemeringkatan web, dan menarik kesimpulan. [12]

\section{HASIL DAN PEMBAHASAN}

Sebuah popularitas dapat di buktikan dengan menggunakan Alexa Rank melalui 3 (tiga) fasilitas Alexa Rank yang dapat digunakan dengan mudah, yakni :

\subsection{Widget Alexa}

Alexa Rank secara terminology adalah nama situs yang memberikan berbagai informasi mengenai kualitas situs lain ataupun website maupun blog, dan Rank berarti ranking atau peringkat. [3] Jadi, alexa rank diartikan sebagai proses ranking mengenai kualitas suatu situs web yang di aplikasikan oleh alexa.com berdasarkan tolak ukur tertentu. Fungsi dari widget alexa rank selain mempromosikan website, juga dapat 
digunakan sebagai pengukur data oleh alexa.com. Dengan memasang widget alexa rank pada website, maka perhitungan akan lebih akurat.

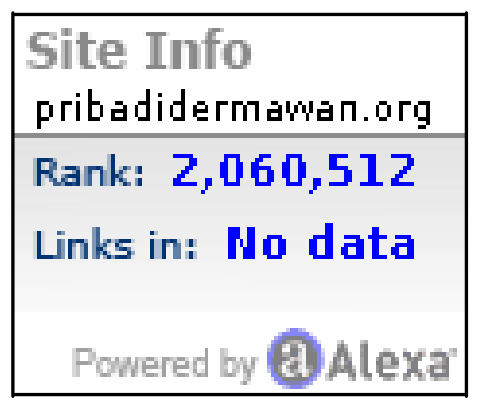

Gambar 2. Widget Alexa Rank

Tampilan pada gambar 2 dapat diperoleh dari input code dengan menambahkan widget HTML yang di letakan di bagian footer website Pribadi Dermawan.

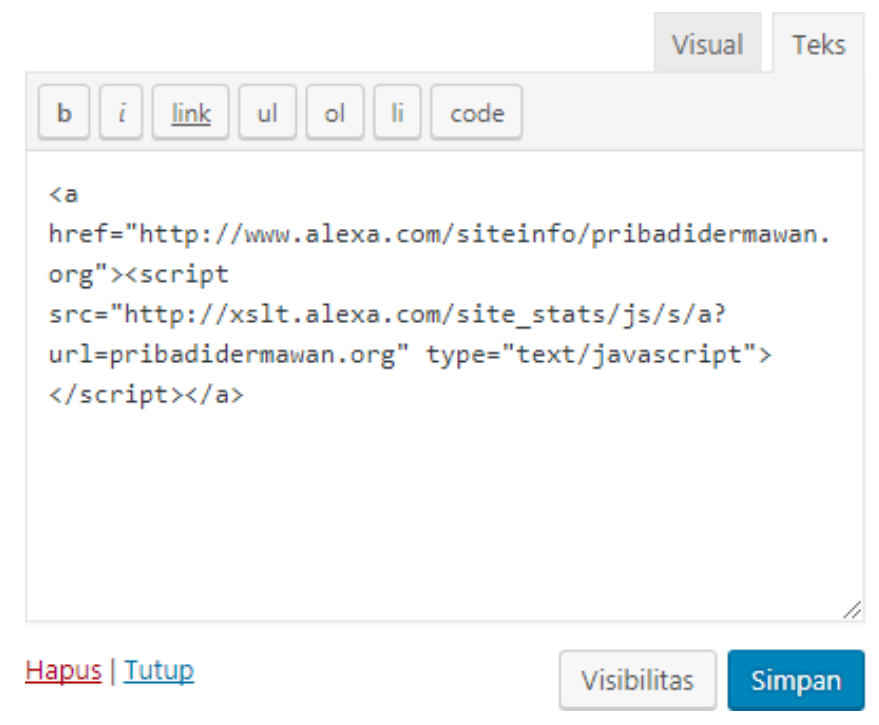

Gambar 3. Code Widget Alexa

Input code pada html harus diperhatikan ketelitiannya karena apabila salah ataupun kurang satu huruf atau satu symbol saja akan mempengaruhi tampilan. Namun dalam penggunaan widget alexa rank jarang sekali diterapkan atau dipasang pada website yang bersangkutan. Dapat diperhatikan, peringkat website pada alexa rank dimulai dari angka yang terkecil sampai yang terbesar, dan ukuran terbesar peringkat alexa rank hingga jutaan ini dikarenakan maraknya penggunaan website pada zaman teknologi canggih ini. Maka, jika peringkat website semakin kecil nilai alexa ranknya maka akan semakin bagus dan dapat dikatakan popular. Ketika sebuah situs web atau 
blog pertama kali mendaftar ke alexa dan memasang widget alexa maka nilai yang di dapat masih sangat besar. Untuk itu banyak website berlomba-lomba untuk memperkecil angka yang diperoleh dengan arti peringkat yang lebih besar. Sehingga dapat membuktikan bahwa website tersebut aktif dan popular.

\subsection{Toolbar Alexa}

Pada situs website crowdfunding salah satunya yaitu website Pribadi Dermawan, mendaftarkan situs ke alexa masih cukup baru dan aktivitas pada website Pribadi Dermawan terbilang masih sedikit sehingga peringkat yang di peroleh masih sangat besar bahkan terkadang naik-turun. Informasi mengenai traffic atau kunjungan dengan alexa berasal dari toolbar alexa yang dipasang pada browser yang digunakan. Dari toolbar tersebut kita dapat mengetahui ranking suatu blog atau website.

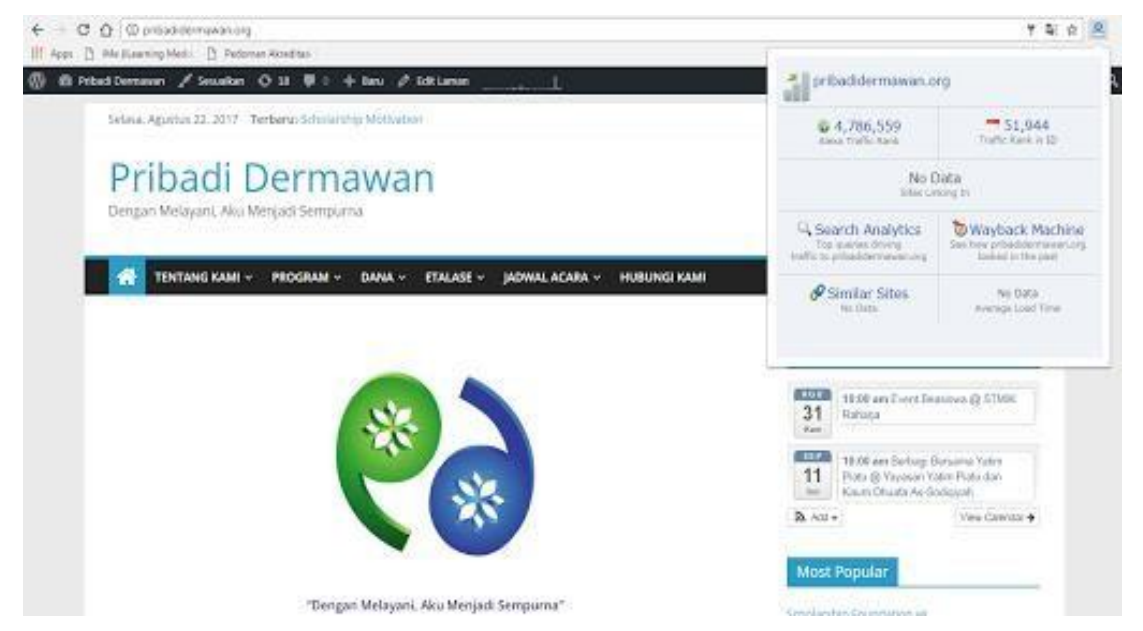

Gambar 4. Alexa Traffic Rank Pribadi Dermawan 22 Agustus 2017

Pada gambar 5 menunjukkan trafik alexa pada website Pribadi Dermawan yang diperoleh pada tanggal 22 Agustus 2017 dimana saat itu awal penggunaan alexa rank pada website Pribadi Dermawan. Pada toolbar alexa dengan website pribadidermawan.org menampilkan Alexa Traffic Rank yaitu perolehan ranking dunia yang sangat besar yaitu 4.786.559, dan perolehan ranking di Indonesia berada di peringkat 51.944 .

36 | Untung, Qurotul, Yustin - Alexa Rank Sebagai Alat Ukur Popularitas... 
Gambar 5. Alexa Traffic Rank Pribadi Dermawan 22 September 2017

Pada gambar 5 menunjukkan bahwa ranking website Pribadi Dermawan pada tanggal 22 September 2017 dengan menggunakan alexa rank memperoleh peringkat 2.405.555 di dunia, dan mendapatkan peringkat 33.392 di Indonesia. Dapat diketahui melalui toolbar alexa rank bahwa peringkat website Pribadi Dermawan mengalami kenaikan yang signifikan selama 1 bulan.

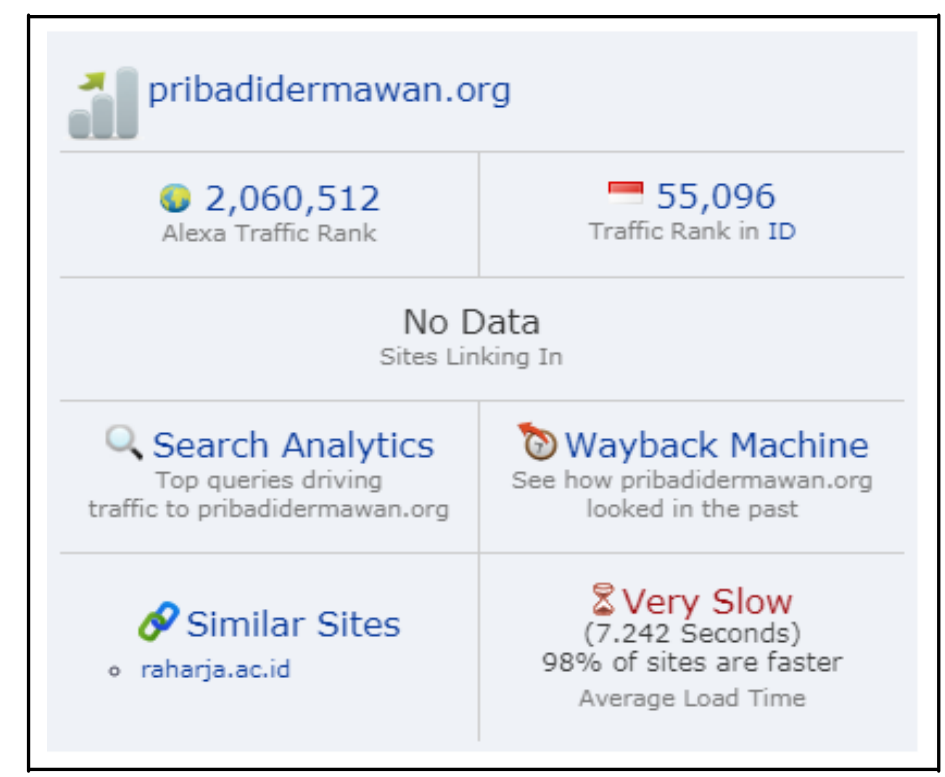

Gambar 6. Alexa Traffic Rank Pribadi Dermawan 21 Oktober 2017

37 | Untung, Qurotul, Yustin - Alexa Rank Sebagai Alat Ukur Popularitas... 
Pada tanggal 21 Oktober 2017, terlihat pada toolbar yang terpasang pada browser bahwa website Pribadi Dermawan pada Alexa Traffic Rank yaitu peringkat 2.060.512 di dunia dan peringkat 55.096 di Indonesia. Hal ini memberikan informasi bahwa perolehan ranking website Pribadi Dermawan bisa mengalami kenaikan atau penurunan peringkat.

\subsection{Site Info Alexa}

Alexa rank indikator peringkat sebuah website berdasarkan trafik atau banyaknya pengunjung yang diberikan atau dibuat oleh alexa.com, data trafik tersebut diambil melalui toolbar alexa pada browser pengunjung website atau blog tersebut.

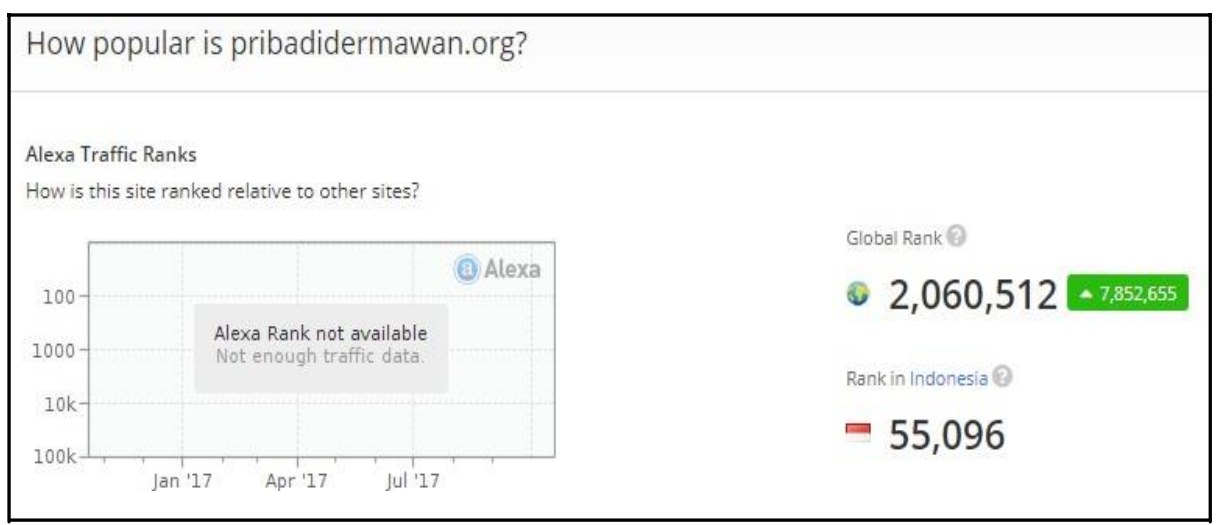

Gambar 6. Popularitas Website Pribadi Dermawan

Sumber : https://www.alexa.com/siteinfo/pribadidermawan.org [11]

Alexa rank dapat mengukur kualitas website melalui alexa.com yaitu website resmi dari Alexa Rank. Setelah di telusuri melalui website alexa.com, Alexa Rank akan menampilkan ranking dari website Pribadi Dermawan baik secara Global atau Negara (asal website) yaitu Indonesia. Pada website pribadidermawan.org berada pada peringkat $2.060 .512 \mathrm{di}$ dunia, naik 345.043 peringkat dari 1 bulan sebelumnya, sedangkan di Indonesia sendiri berada pada peringkat 55.096.

\begin{tabular}{|c|c|c|}
\hline \multicolumn{3}{|c|}{ How engaged are visitors to pribadidermawan.org? } \\
\hline Bounce Rate & Daily Pageviews per Visitor & Daily Time on Site \\
\hline $45.30 \%-24.00 \%$ & $4.50 \cdot 343046$ & $9: 47-10.00 \%$ \\
\hline
\end{tabular}

Gambar 7. Keterlibatan Pengunjung

38 | Untung, Qurotul, Yustin - Alexa Rank Sebagai Alat Ukur Popularitas... 
Selain itu, alexa rank juga menampilkan bounce rate dengan persentase $45.30 \%$ dimana bounce rate yaitu suatu nilai dalam persentase dalam artian jumlah pengunjung yang langsung meninggalkan blog atau website Pribadi Dermawan setelah membuka sebuah halaman. Disamping kanan terdapat daily pageviews per visitor dengan angka $4.50 \%$ dengan maksud bahwa rata rata visitor tiap harinya adalah 4.50. Kemudian daily time on site pada Pribadi Dermawan yaitu 9:47 adalah waktu lama (mm:ss) pengunjung tiap harinya mengunjungi website Pribadi Dermawan.

\section{KESIMPULAN}

Berdasarkan penelitian yang telah dilakukan pada website crowdfunding Pribadi Dermawan, dapat ditarik kesimpulan dimana terdapat 3 (tiga) kesimpulan, adapun diantaranya :

1. Pemanfaatan toolbar Alexa Rank sangat membantu website agar dapat selalu terpacu untuk meningkatkan traffic rank webiste Pribadi Dermawan.

2. Informasi lengkap mengenai ranking website Pribadi Dermawan dapat diketahui dari site info alexa yang menampilkan dari berbagai jenis popularitas.

3. Alexa Rank dapat digunakan sebagai alat ukur popularitas website crowdfunding Pribadi Dermawan.

\section{SARAN}

Penelitian ini agar dapat menjadi acuan untuk peneliti selanjutnya agar peringkat website Pribadi Dermawan meningkat. Berdasarkan analisis dan implementasi yang sederhana, diharapkan hasil penelitian dapat menjadi salah satu bentuk pengarahan agar upaya-upaya peningkatan rank pada website crowdfunding Pribadi Dermawan di tingkatkan.

\section{DAFTAR PUSTAKA}

[1] Pribadi Dermawan. http///pribadidermawan.org/. diakses tanggal 15 Oktober 2017

[2] Wikipedia. Rank. https:/en.wikipedia.org/wiki/Rank. diakses tanggal 15 Oktober 2017

[3] Widayanti, R., \& Utsalina, D. S. (2015). ANALISIS SITUS WEB PERUSAHAAN JASA PENGIRIMAN BARANG MENGGUNAKAN PERANGKAT PEMERINGKATAN ALEXA. SMATIKA, 5(1).

[4] Rahardja, U., Aini, Q., \& Meytasari, R. (2017). Pemanfaatan Fungsi Etalase Artikel Untuk Meningkatkan Traffic Rank Website ZPreneur. Technomedia Journal, 1(2), 75-89.

39 | Untung, Qurotul, Yustin - Alexa Rank Sebagai Alat Ukur Popularitas... 
[5] Prasetya, A., \& Rahmawati, L. S. (2015). ANALISIS WEBSITE TOKO ONLINE. JURNAL TEKNOLOGI INFORMASI: Teori, Konsep, dan Implementasi, 6(1), 1922.

[6] Novita, D., (2016). ANALISIS POPULARITAS WEBSITE PEMERINTAH DAERAH DI SUMATERA SELATAN. Konferensi Nasional Teknologi Informasi \& Aplikasinya, 4.

[7] Rahardja, U., Aini, Q., \& Sulastrini, L. R. (2017). Penerapan Inbound Official Site Sistem Informasi Untuk Meningkatkan Rank Webometrics. Technomedia Journal, 1(2), 106-117.

[8] Rahardja, U., Dewi, E. N., \& Lutfiani, N. (2017). Peningkatan Rank Webometrics Menggunakan Metode Inbound Dan Outbound Pada Perguruan Tinggi. SISFOTENIKA, 7(1).

[9] Thakur, A., Sangal, A. L., \& Bindra, H. (2011). Quantitative measurement and comparison of effects of various search engine optimization parameters on Alexa Traffic Rank. International Journal of Computer Applications, 26(5), 15-23.

[10] Solihin, A. (2011). Strategi Peningkatan Peringkat Perguruan Tinggi di Webometric: Studi Kasus Universitas Budi Luhur. In Prosiding Seminar Nasional Multidisiplin Ilmu.

[11] Site Info Alexa, Website Pribadi Dermawan, https:/www.alexa.com/siteinfo/pribadidermawan.org, diakses tanggal 21 Oktober 2017

[12] Hariadi, M., \& Suprapto, Y. K. (2011). PERINGKAT WEBSITE PERGURUAN TINGGI BERBASIS ANALISA HYPERLINK MENGGUNAKAN FACTOR ANALYSIS. Kursor, 6(1), 27-36.

40 | Untung, Qurotul, Yustin - Alexa Rank Sebagai Alat Ukur Popularitas... 